Article

\title{
Production Characteristics with Different Superimposed Modes Using Variogram: A Case Study of a Super-Giant Carbonate Reservoir in the Middle East
}

\author{
Chenji Wei ${ }^{1}$, Hongqing Song ${ }^{2, *}$, Yong Li $^{1}$, Qi Zhang ${ }^{1}$, Benbiao Song ${ }^{1}$ and Jiulong Wang ${ }^{2}$ \\ 1 Research Institute of Petroleum Exploration and Development, PetroChina, Beijing 100083, China; \\ weichenji@petrochina.com.cn (C.W.); liyong@petrochina.com.cn (Y.L.); \\ zhangqi125@petrochina.com.cn (Q.Z.); songbenbiao@petrochina.com.cn (B.S.) \\ 2 School of Civil and Environmental Engineering, University of Science and Technology Beijing, \\ Beijing 100083, China; jiulong20080919@126.com \\ * Correspondence: songhongqing@ustb.edu.cn
}

Academic Editor: Alireza Bahadori

Received: 30 August 2016; Accepted: 6 February 2017; Published: 18 February 2017

\begin{abstract}
Heterogeneity of permeability is an important factor affecting the production of a carbonate reservoir. How to correctly characterize the heterogeneity of permeability has become a key issue for carbonate reservoir development. In this study, the reservoirs were categorized into four superimposed modes based on the actual logging data from a super-giant heterogeneous carbonate reservoir in the Middle East. A modified permeability formula in terms of the variogram method was presented to reflect the heterogeneity of the reservoirs. Furthermore, the models of oil production and water cut were established and the analytical solutions were obtained. The calculation results show that the present model can predict the productivity of wells with different heterogeneous layers more accurately and rapidly. The larger the varigoram value, the stronger the heterogeneity of the reservoirs, and the faster the decline of production owing to a quicker reduction of formation pressure. With the increase in variogram value, the relative permeability of the oil phase is smaller and the water phase larger, and the water cut becomes larger. This study has provided a quick and reasonable prediction model for heterogeneous reservoir.
\end{abstract}

Keywords: carbonate reservoir; production decline; superimposed mode; variogram; water cut

\section{Introduction}

There are two factors to influence oil recovery, which are geological conditions and development plans [1]. The former are inherent characteristics of reservoirs, such as heterogeneity, viscosity, wettability, capillary pressure, gravity, and so on $[2,3]$. The latter is related to the development design and technological measures, such as well spacing density, water injection, etc. [4]. The heterogeneity of vertical permeability is one of the most important factors to influence the reservoir oil recovery.

Carbonate rock is one of the most important oil and gas reservoir formations in the world, which reflects about half of the global reserves. The output has reached more than $60 \%$ of the total output. Compared with the conventional sandstone reservoir, the degree of exploration and development for carbonate reservoir is lower. Carbonate reservoirs have typical characteristics of dual media and serious permeability heterogeneity, which leads to poor development effects.

At present, there are two aspects to study permeability heterogeneity. On the one hand, the permeability heterogeneity is characterized by permeability variation coefficient and ratio of vertical permeability to horizontal permeability [5], and then the effects of heterogeneity are analyzed 
by theoretical calculations utilizing modified average permeability [6,7]. However, these methods can not characterize the randomness of the regional variables and represents the distribution of the strata heterogeneity. On the other hand, numerical simulation is used to study heterogeneity directly with different permeability layers [8,9]. Although the geological model established for numerical simulation is closer to the real reservoir, the simulation processes are complicated and time consuming [10].

The variogram is a method of moment estimation proposed by Motheron (1965), and it is a specific research tool in geological statistics [11], which can not only express the spatial structure with the regional variables, or characterize the randomness of the regional variables, but also reflects the change degree of the regional variables in a certain distance range and direction [12]. This method can reflect the change degree of the regional variables. In the process of the development of carbonate reservoirs, variogram analyses could be conducted to characterize the heterogeneity of their properties at the outcrop scale [13].

In this paper we, firstly, classified the heterogeneous reservoirs into four superimposed modes using the actual logging data from a super-giant carbonate reservoir in the Middle East. Then a new permeability model considering the heterogeneity was established with the variogram method. In addition, we verified our model with actual production data and the results show that the present model can predict the productivity of wells with different heterogeneous layers more accurately and rapidly. Finally, the analysis of variogram values was carried out to determine the relationship with oil production, relative permeability and water cut in a heterogeneous carbonate reservoir. The results could provide new insights and theoretical bases for the development of heterogeneous reservoirs.

\section{Study Area}

The oilfield studied in this paper is located in the north of the massif terrace of Arabia Peninsula. The geological strata is relatively stable, and there is almost no fault. The main rock lithology is carbonate and sandstone. Carbonate reservoirs usually have the characteristics of large lithologic variation, multiple reservoir types, and strong heterogeneity $[14,15]$. The oilfield studied in this paper is a typical carbonate reservoir with a heterogeneity of vertical permeability [16], and there is a great difference of geological structure and superimposed mode in different areas. According to the different values of permeability, we can divide formation into five types, which are tight type, low type, I type, II type, and III type. Furthermore the four superimposed modes were established in terms of the different ratios of permeability shown in Figure 1. The details of the parameters can be found in Table 1.

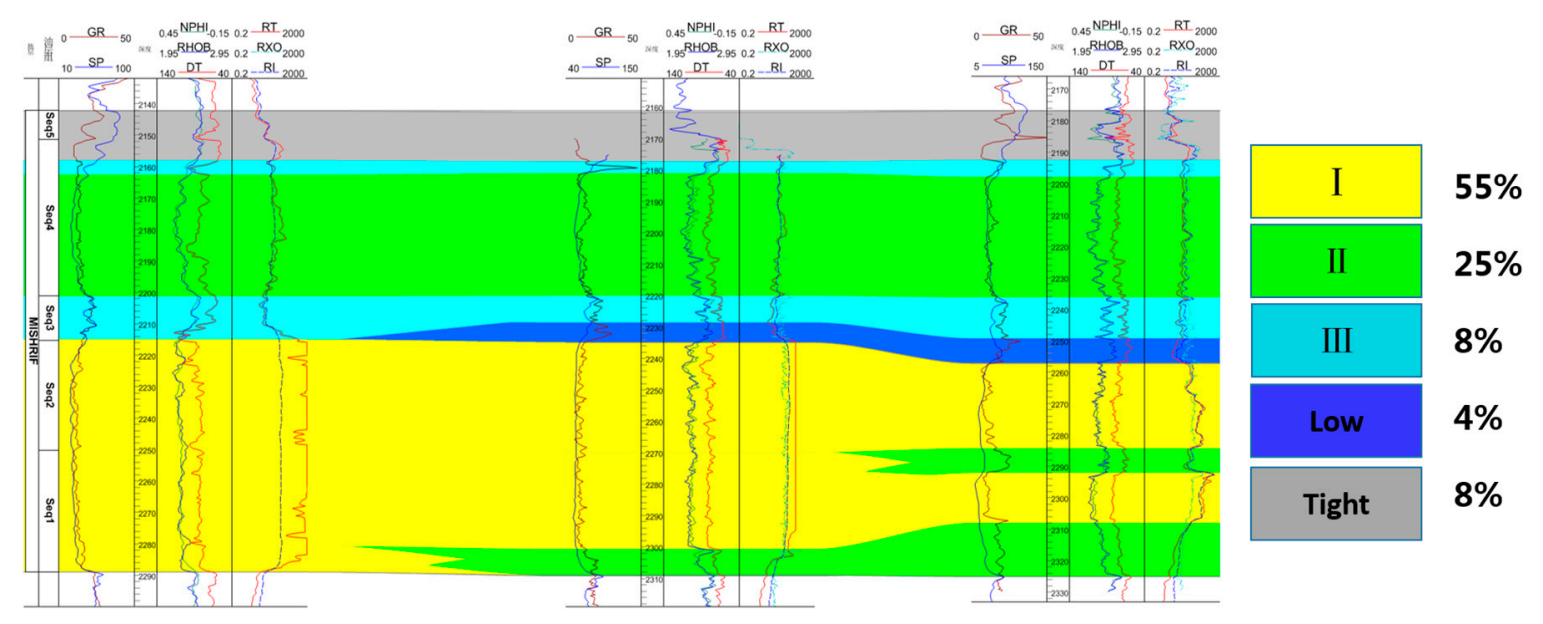

(a)

Figure 1. Cont. 


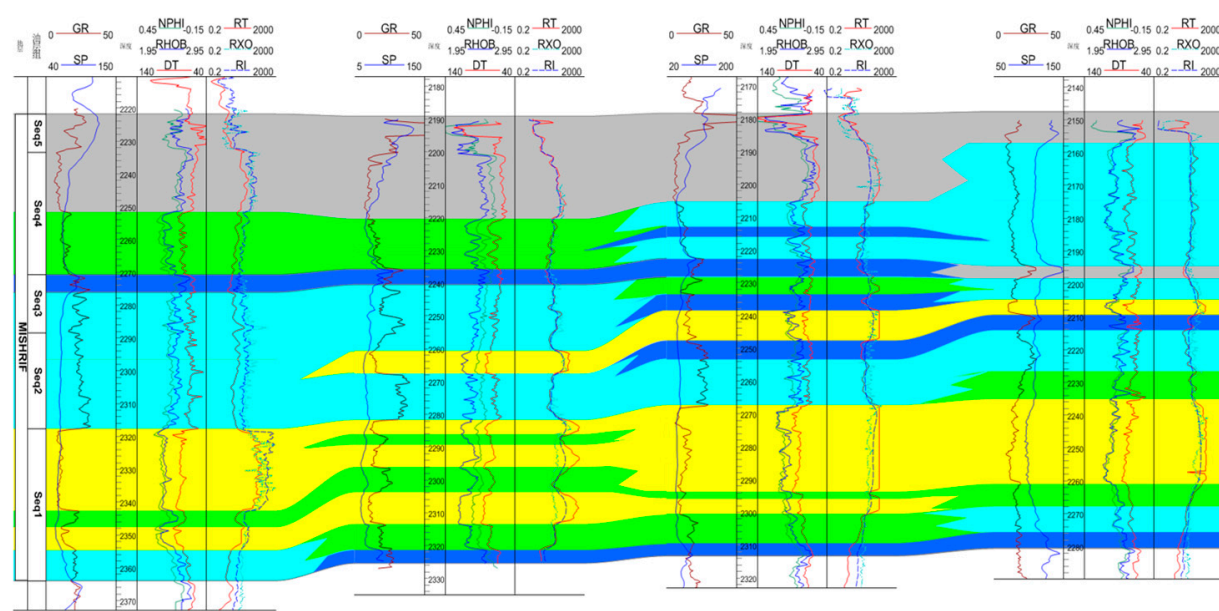

\begin{tabular}{|c|c|}
\hline I & $20 \%$ \\
\hline \hline II & $25 \%$ \\
\hline \hline III & $30 \%$ \\
\cline { 1 - 1 } Low & $10 \%$ \\
\cline { 1 - 1 } Tight & $15 \%$ \\
\hline
\end{tabular}

(b)
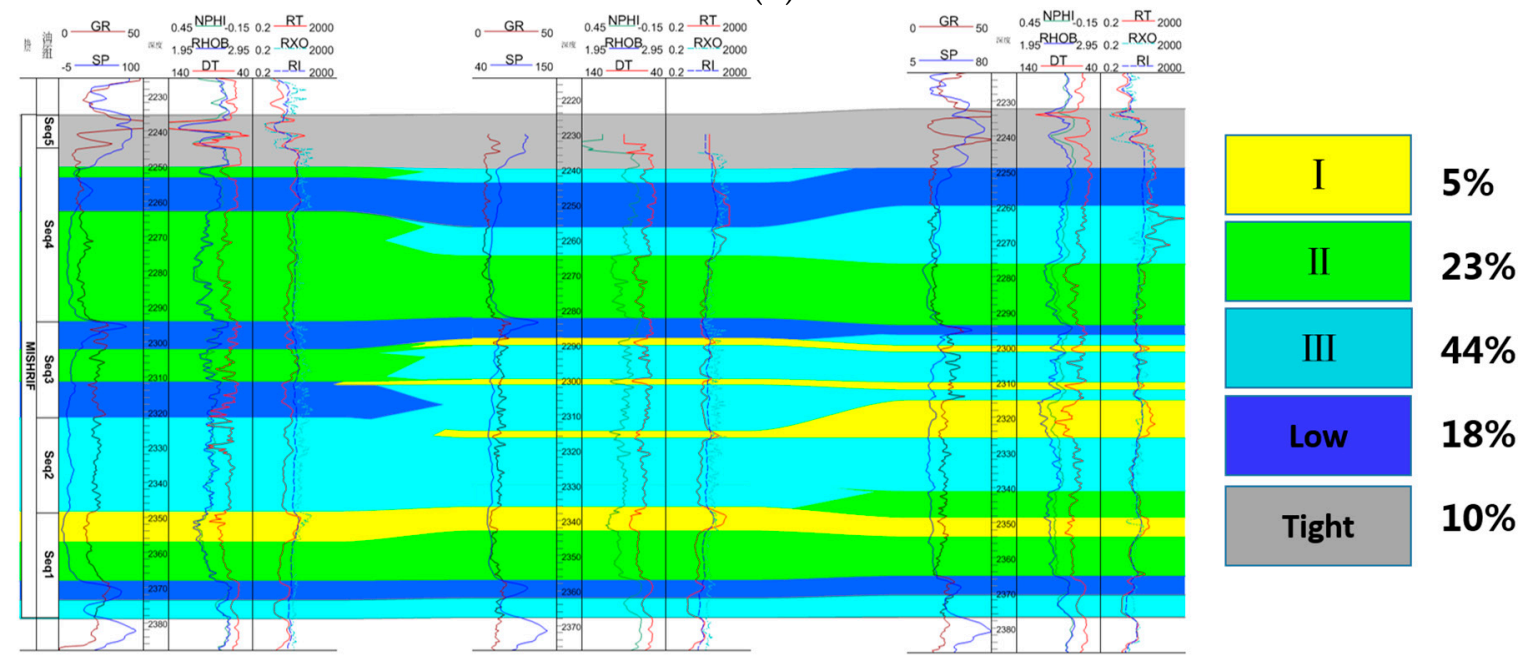

(c)
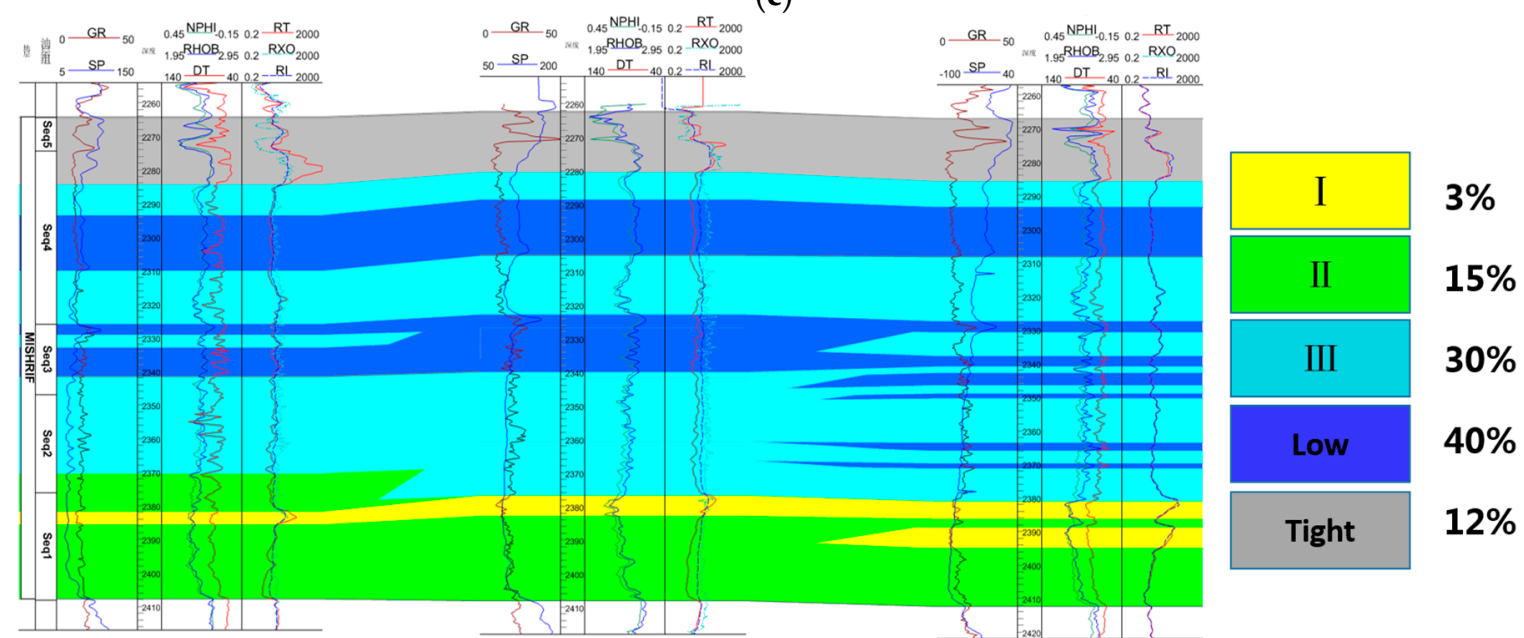

(d)

Figure 1. The schematic of four superimposed modes: (a) superimposed mode A; (b) superimposed mode B; (c) superimposed mode C; (d) superimposed mode D. 
Table 1. The permeability distribution of the different superimposed modes.

\begin{tabular}{cccccc}
\hline \multirow{2}{*}{$\begin{array}{c}\text { Reservoir } \\
\text { Types }\end{array}$} & $\begin{array}{c}\text { Permeability } \\
(\mathbf{m D})\end{array}$ & $\begin{array}{c}\text { Superimposed } \\
\text { Mode A }\end{array}$ & $\begin{array}{c}\text { Superimposed } \\
\text { Mode B }\end{array}$ & $\begin{array}{c}\text { Superimposed } \\
\text { Mode C }\end{array}$ & $\begin{array}{c}\text { Superimposed } \\
\text { Mode D }\end{array}$ \\
\hline I Type & $100-150$ & 55 & 20 & 5 & 3 \\
II Type & $70-100$ & 25 & 25 & 23 & 15 \\
III Type & $40-70$ & 8 & 30 & 44 & 30 \\
Low & $10-40$ & 4 & 10 & 18 & 40 \\
Tight & $5-10$ & 8 & 15 & 10 & 12 \\
\hline
\end{tabular}

Figure 2 is the permeability distribution of four kinds of superimposed mode. We can conclude that the distribution of the superimposed modes $\mathrm{A}$ and $\mathrm{D}$ is near linear, and the distribution of the superimposed modes $B$ and $C$ tend toward a normal distribution. Thus, the superimposed modes $B$ and $\mathrm{C}$ are more heterogeneous than the superimposed modes $\mathrm{A}$ and D [17].

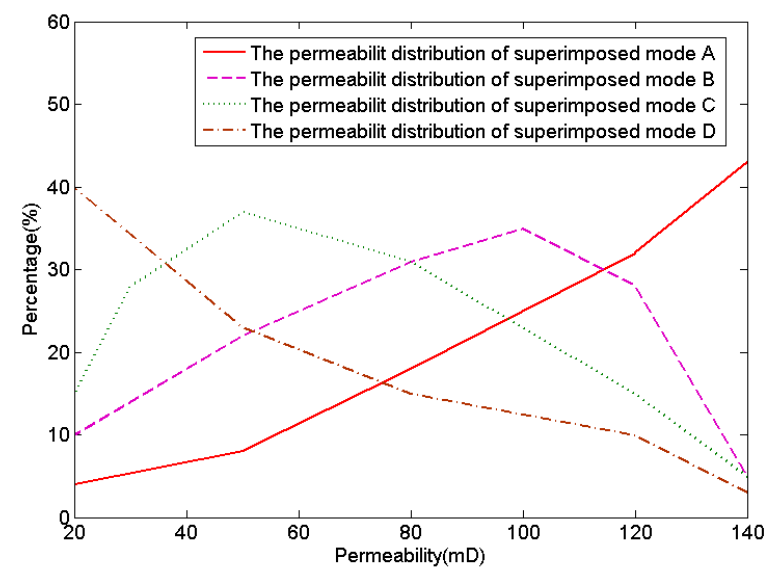

Figure 2. Schematic of permeability distribution of different superimposed modes.

\section{Methods}

The development of a carbonate oilfield has two exploitation stages. In the first stage, the driving force of the oil production is the original pressure and energy of the formation. The formation pressure gradually decreases with the development of the oil reservoir, which will lead to a significant decline of production. We can enhance oil recovery through the method of water-flooding. The oilfield studied in this paper began to use water-flooding in 2010.

\subsection{Elastic Exploitation}

The formation pressure gradually decreases with the development of the oil reservoir, and the change of formation pressure with time is satisfied as follows [18]:

$$
\left\{\begin{array}{c}
\frac{\partial^{2} p}{\partial r^{2}}+\frac{1}{r} \frac{\partial p}{\partial r}=\frac{1}{\chi} \frac{\partial p}{\partial t} \\
\chi=\frac{K}{\phi \mu C_{\mathrm{t}}}
\end{array}\right.
$$

where $K$ is the permeability of the reservoir, $\mathrm{m}^{2} ; \phi$ is the porosity, $\%$; $\mu$ is the viscosity of fluid, $\mathrm{Pa} \cdot \mathrm{s}$; and $C_{t}$ is the compressibility, $\mathrm{MPa}^{-1}$.

Define:

$$
u=\frac{r^{2}}{4 \chi t}
$$

where $u$ is dimensionless. 
When the pressure of inner or outer boundary is constant, Equation (1) can be derived as follows:

$$
\left\{\begin{array}{l}
u \frac{\mathrm{d}^{2} p}{\mathrm{~d} u^{2}}+\frac{\mathrm{d} p}{\mathrm{~d} u}(1+u)=0(0<u<\infty) \\
p(u=0)=p w \\
p(u=450)=p e
\end{array}\right.
$$

where $p w$ is the pressure under the conditions of $u=0$, and $p e$ is the pressure under the conditions of $u=450$.

We can get the pressure distribution equation by solving Equation (2).

$$
p(u)=p e-\operatorname{Ei}(1, u)(0.0365384234 p w-0.0365384234 p e)
$$

Then

$$
p(r, t)=p e-\operatorname{Ei}\left(1, \frac{r^{2}}{4 \chi t}\right)(0.0365384234 p w-0.0365384234 p e)
$$

We have analyzed the heterogeneity of the reservoir using variogram [19].

$$
\begin{gathered}
\gamma\left(h_{d}\right)=\frac{1}{2 N\left(h_{d}\right)} \sum_{i=1}^{N\left(h_{d}\right)}\left[Z\left(k_{i}\right)-Z\left(k_{i}+h_{d}\right)\right]^{2} \\
K_{c}=\bar{K} \pm \sqrt{2 \gamma\left(h_{d}\right)}
\end{gathered}
$$

where $\bar{K}=\sum_{i=1}^{n} h_{i} k_{i} / h_{t}, h_{d}$ is the lag distance, $N(h)$ is the variation capacity, $h_{i}$ is the thickness of layer $i, k_{i}$ is the permeability of layer $i$, and $h_{t}$ is the total thickness of the reservoir; $K_{c}$ is the equivalent permeability.

According to the Darcy's law:

$$
Q=\frac{K_{c} A}{\mu} \frac{\mathrm{d} p}{\mathrm{~d} r}
$$

Then we can get the production near wellbore:

$$
Q=\frac{K_{c} A}{\mu} \frac{p\left(r_{w}+\Delta r, t\right)-p w}{\Delta r}
$$

where $r_{w}$ is the shaft radius, $A$ is the cross-section area of reservoir and $Q$ is the flow rate.

\subsection{Water-Flooding}

The oil production decreased gradually with the decrease of formation pressure. In order to stabilize the oil production, we use the way of water-flooding to supplement the formation energy, and the flow resistance of each layer changes with the flood front. Take the case of superimposed mode A; we have analyzed the flow resistance of oil-water two phase flow in the process of water flooding, and obtained the water injection rate of each small layer [20].

$$
R_{i}=\frac{1}{2 \pi h_{i, j} k_{i, j} f_{i, 1}} \ln \frac{r_{i, 1}}{r_{w}}+\cdots+\frac{1}{2 \pi h_{i, j} k_{i, j} f_{i, n}} \ln \frac{r_{e}}{r_{n}}
$$

where $f_{i, n}=\frac{k_{r o i, n}}{\mu_{0}}+\frac{k_{r v i, n}}{\mu_{w, n}}$ is the slug fluidity, $i$ is the number of the laye and $R_{i}$ is resistance of layer $i$. This present model is the oil-water two phase flow model, so $j=1,2$.

The water injection rate of each layer can be expressed as:

$$
Q_{i}=\frac{p_{e}-p_{w}}{R_{i}}=\frac{\frac{1}{R_{i}}}{\frac{1}{R_{1}}+\frac{1}{R_{2}} \cdots+\frac{1}{R_{i}}} Q_{w}
$$

where $Q_{w}$ is total water injection rate. 
In this paper, we divide the formation into five layers, and the flow resistance of each layer is as follows:

$$
\begin{aligned}
& R_{1}=\frac{1}{2 \pi h_{1} k_{1} f_{1,1}} \ln \frac{r_{1,1}}{r_{w}}+\frac{1}{2 \pi h_{1} k_{1} f_{1,2}} \ln \frac{r_{e}}{r_{1,1}} \\
& R_{2}=\frac{1}{2 \pi h_{2} k_{2} f_{2,1}} \ln \frac{r_{2,1}}{r_{w}}+\frac{1}{2 \pi h_{2} k_{2} f_{2,2}} \ln \frac{r_{e}}{r_{2,1}} \\
& R_{3}=\frac{1}{2 \pi h_{3} k_{3} f_{3,1}} \ln \frac{r_{3,1}}{r_{w}}+\frac{1}{2 \pi h_{3} k_{3} f_{3,2}} \ln \frac{r_{e}}{r_{3,1}} \\
& R_{4}=\frac{1}{2 \pi h_{4} k_{4} f_{4,1}} \ln \frac{r_{4,1}}{r_{w}}+\frac{1}{2 \pi h_{4} k_{4} f_{4,2}} \ln \frac{r_{e}}{r_{4,1}} \\
& R_{5}=\frac{1}{2 \pi h_{5} k_{5} f_{5,1}} \ln \frac{r_{5,1}}{r_{w}}+\frac{1}{2 \pi h_{5} k_{5} f_{5,2}} \ln \frac{r_{e}}{r_{5,1}}
\end{aligned}
$$

The relative permeability model in this paper is as follows:

$$
\begin{gathered}
K_{r o}=k r o_{\max }-\frac{k r o_{\max } \times\left(s o_{\max }-s o\right)^{n}}{\left(s o_{\max }-s o r\right)^{n}} \\
K_{r w}=\frac{k r w_{\max } \times(s w-s w r)}{\left(s w_{\max }-s w r\right)^{m}}
\end{gathered}
$$

where $s o+s w=1$, so is the oil saturation, $s o_{\max }$ is the maximum oil saturation, sor is the residual oil saturation, $s w$ is the water saturation, $s w_{\max }$ is the maximum water saturation, swr is the irreducible water saturation, $K_{r o}$ is the oil relative permeability, and $K_{r w}$ is the water relative permeability, and $m$ and $n$ are characteristic constants.

$f_{w}$ (water cut ) can be expressed as follows considering the influence of capillary pressure and gravity:

$$
f_{w}=\frac{1+\frac{K_{r o}}{\mu_{r o}} \frac{1}{v_{t}}\left(\frac{\partial p_{c}}{\partial x}-\Delta \rho \cdot g \sin \alpha\right)}{1+\frac{\mu_{w w}}{\mu_{0}} \frac{K_{r o}}{K_{r w}}}
$$

\subsection{The Procedure of Simulation}

Figure 3 is the simulation procedure. We can see the whole simulation process clearly through the flowchart. Firstly, the formation parameters are input into the model, then the variogram value of the whole reservoir is calculated. By comparing the parameters of well logging and seismic data, the error analysis is carried out. Then the optimal equivalent permeability is obtained through repeated calculation. Finally, the optimal model is used in the fitting and prediction. Table 2 is the parameter list for simulations.

Table 2. Parameter list for simulations.

\begin{tabular}{cccc}
\hline Parameter & Value & Parameter & Value \\
\hline$n$ (dimensionless) & 2.3 & $p_{e}(\mathrm{MPa})$ & 6 \\
$m$ (dimensionless) & 1.4 & $p_{e}(\mathrm{MPa})$ & 26 \\
$\phi$ & 0.2 & $r_{e}(\mathrm{~m})$ & 500 \\
$\mu_{o}(\mathrm{~Pa} \cdot \mathrm{s})$ & $2.7 \times 10^{-3}$ & $r_{w}(\mathrm{~m})$ & 0.1 \\
$\mu_{w}(\mathrm{~Pa} \cdot \mathrm{s})$ & $1 \times 10^{-3}$ & $h_{t}(\mathrm{~m})$ & 100 \\
$C_{t}\left(\mathrm{MPa}^{-1}\right)$ & $1 \times 10^{-7}$ & & \\
\hline
\end{tabular}




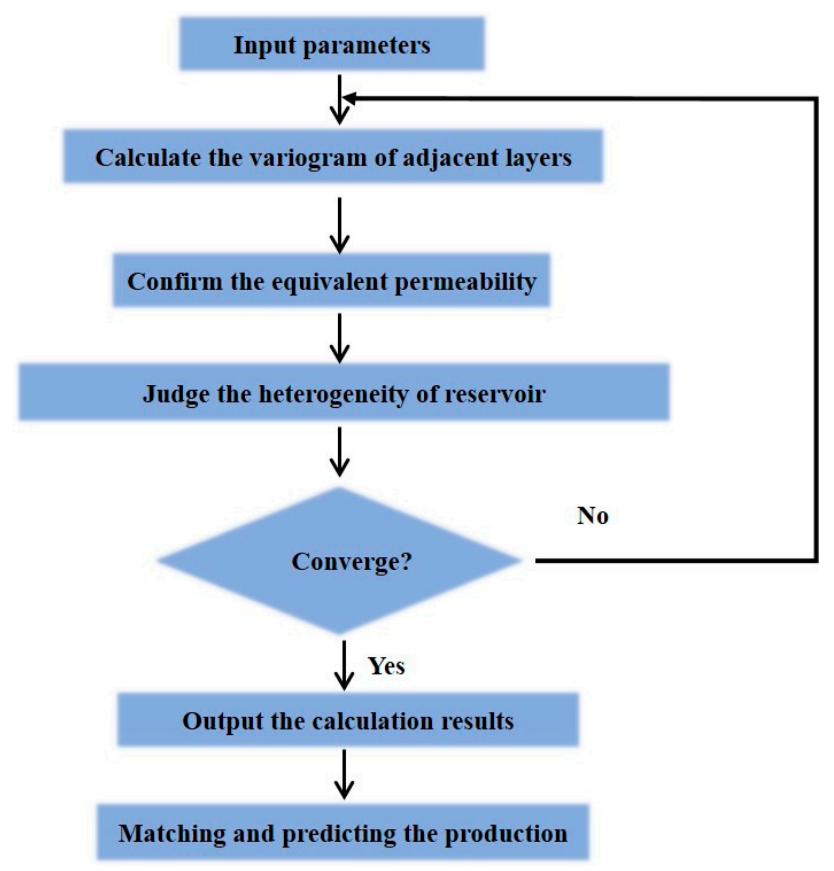

Figure 3. The flow chart of simulation.

\section{Results and Discussion}

In this paper, we compared the actual production data of a super-giant carbonate reservoir in the Middle East with the present model calculation, and the results showed that the present model could predict the productivity of wells in heterogeneous reservoirs more accurately and rapidly. Then, we analyzed the influence of the variogram value on the oil productivity, the relative permeability, and the water cut. Table 3 shows the production data of four wells with different superimposed modes.

Table 3. The production data of four superimposed modes/wells.

\begin{tabular}{|c|c|c|c|c|}
\hline Time (d) Model & $\begin{array}{l}\text { Superimposed } \\
\text { Mode A(t/d) }\end{array}$ & $\begin{array}{l}\text { Superimposed } \\
\text { Mode } B(t / d)\end{array}$ & $\begin{array}{l}\text { Superimposed } \\
\text { Mode C(t/d) }\end{array}$ & $\begin{array}{l}\text { Superimposed } \\
\text { Mode } D(t / d)\end{array}$ \\
\hline 0 & 1000.00 & 714.29 & 553.00 & 382.71 \\
\hline 120 & 857.14 & 622.14 & 511.57 & 335.29 \\
\hline 240 & 714.29 & 642.86 & 465.14 & 295.57 \\
\hline 360 & 636.00 & 601.43 & 437.86 & 271.86 \\
\hline 480 & 571.43 & 579.00 & 424.86 & 248.86 \\
\hline 600 & 500.00 & 547.57 & 393.57 & 239.57 \\
\hline 720 & 442.86 & 488.43 & 378.71 & 234.71 \\
\hline 840 & 422.57 & 471.43 & 356.57 & 191.71 \\
\hline 960 & 404.43 & 424.00 & 304.71 & 147.57 \\
\hline 1080 & 382.43 & 396.29 & 295.00 & 147.43 \\
\hline 1200 & 352.43 & 376.14 & 276.43 & 138.29 \\
\hline 1320 & 322.57 & 368.71 & 271.43 & 133.29 \\
\hline 1440 & 285.71 & 361.86 & 281.14 & 138.29 \\
\hline 1560 & 165.29 & 330.00 & 266.71 & 133.29 \\
\hline 1680 & 163.29 & 313.29 & 244.29 & 124.43 \\
\hline
\end{tabular}

\subsection{The Comparison of Actual Production and the Present Model Calculation}

Figure 4 displays the comparison of actual production data and the present model with different superimposed modes. The result shows that the present model can reflect the law of real production decline and predict the productivity of heterogeneous reservoirs easily and accurately. Due to 
more heterogeneity, the production declines of superimposed modes B and C are larger than the superimposed modes A and D under the same thickness.
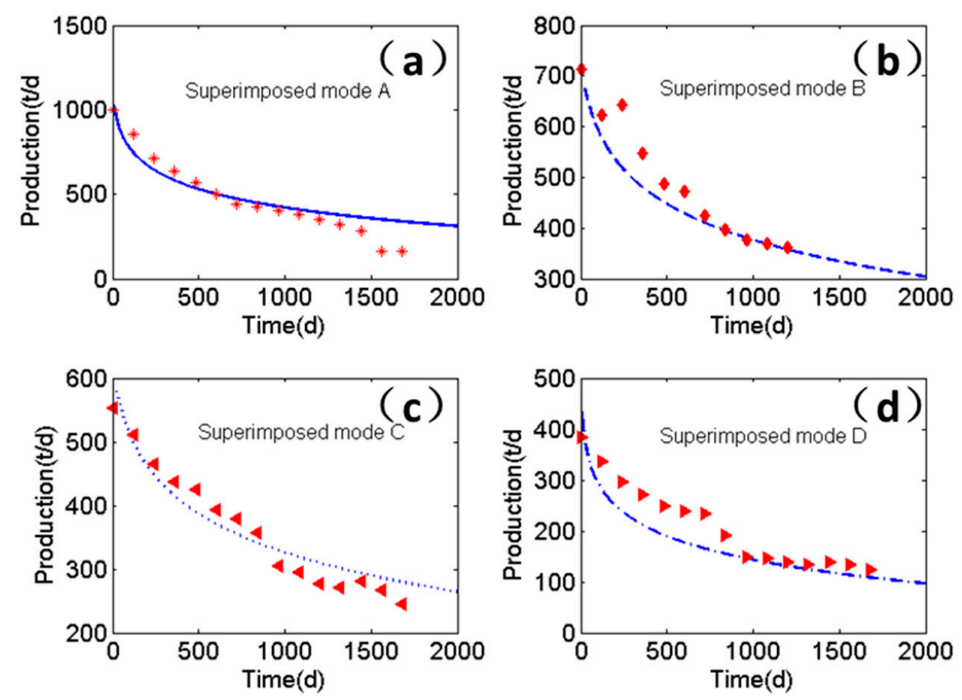

Figure 4. Comparison of actual production data and the present model with different superimposed modes: (a) superimposed mode A; (b) superimposed mode B; (c) superimposed mode C; (d) superimposed mode D.

\subsection{Effect of Variogram Value on Production}

Figure 5 shows the relationship between production and time with different variogram values. Figure 5 shows that the larger the varigoram value, the stronger the heterogeneity of reservoirs, and the faster decline of production. The stronger heterogeneity of the reservoir would lead to a reduction of the formation pressure more quickly.

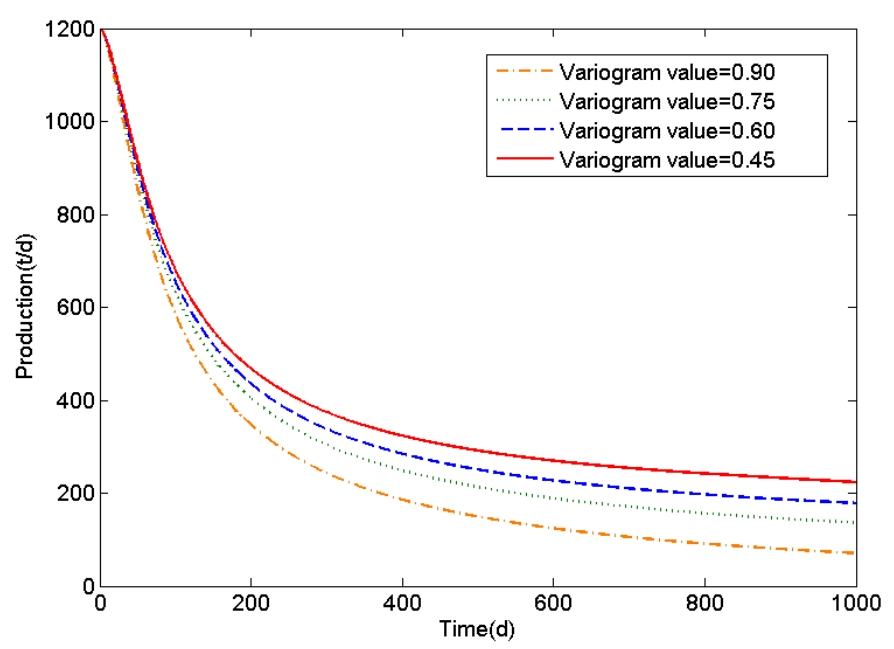

Figure 5. Production with different variogram values.

\subsection{Effect of Variogram Value on Water Cut}

Figure 6 displays the relationship between the water cut and times with different variogram values. As shown in Figure 6, the water cut becomes larger with the increase in the variogram value. This means that the heterogeneity of the reservoir would be stronger with the increase of variogram value, which leads to faster water movement in high permeability layer than low permeability layer. 


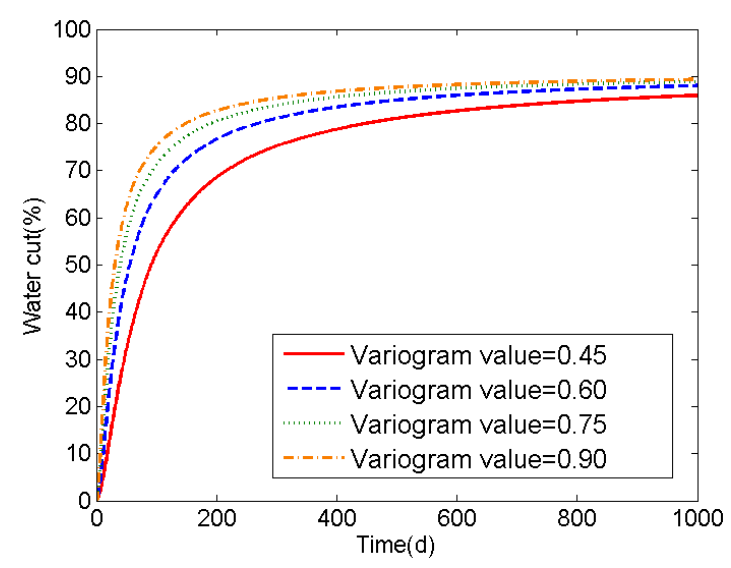

Figure 6. Water cuts with different variogram values.

\subsection{Effect of Variogram Value on Relative Permeability}

Figure 7 shows relative permeability curves with different variogram values. The results show that the relative permeability of the oil phase is larger and the water phase is smaller with the decrease of the variogram value. The reason why is that the smaller variogram value is, the weaker the heterogeneity of reservoir, and then the water-free oil production period is longer, and the water cut rises slower.

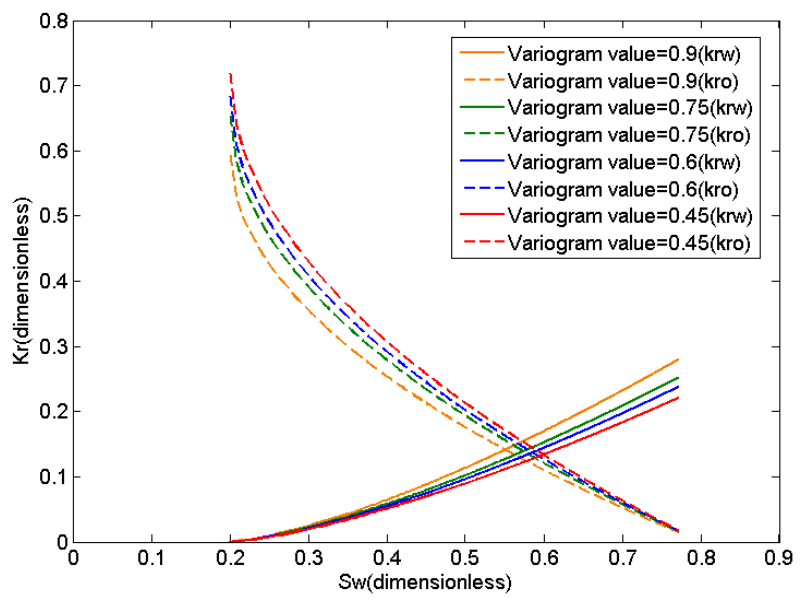

Figure 7. Relative permeability with different variogram values.

\subsection{The Advantages and Limitations of the Present Method}

In this paper, the $2 \mathrm{D}$ variogram method is used to characterize the heterogeneity of carbonate reservoirs. Firstly, the 2D model can rapidly calculate the variation of the permeability in single direction, which can describe the heterogeneity of reservoir qualitatively. In addition, 2D model can provide more targeted understanding of the influence of the heterogeneity on development in single direction. However, the 2D model also has some limitations compared to 3D model. The impact of the reservoir development is various, and the 2D model cannot analyze the impact of all the factors, which leads to the inconsistency between theoretical analysis and engineering practice. We mainly study the effect of vertical heterogeneity on reservoir productivity in this paper, so the 2D model is more efficient.

\section{Conclusions}

The reservoirs were categorized into four superimposed modes using the actual logging data from a super-giant heterogeneous carbonate reservoir in the Middle East. A modified permeability formula 
in terms of the variogram method was presented to reflect the heterogeneity of reservoir. Based on the modified permeability formula, the models of oil production and water cut were established and the analytical solutions were obtained.

The results show that the present model can predict the productivity of a well with different heterogeneous layers more accurately and rapidly. Due to greater heterogeneity, the production declines if superimposed modes B and C are larger than the superimposed modes A and D under the same thickness. The larger the varigoram value, the stronger heterogeneity of reservoirs, the faster the decline of production owing to a quicker reduction of formation pressure. With the increase of the variogram value, the relative permeability of the oil phase is smaller and the water phase larger, and the water cut becomes larger.

This study has provided a quick and reasonable prediction model for heterogeneous reservoir development.

Acknowledgments: We gratefully acknowledge the PetroChina Science and Technology Major Project under Grant 2011E-2501 and the National Nature Science Foundations of China under Grant 51404024 for financial support.

Author Contributions: Chenji Wei proposed this topic and provided the actual data of oilfield. Hongqing Song and Yong Li supervised the work. Qi Zhang, Benbiao Song and Jiulong Wang were in charge of model establishment and analytical solution. Jiulong Wang organized the manuscript. All authors read and approved the final manuscript.

Conflicts of Interest: The authors declare no conflict of interest.

\section{Nomenclature}

$\begin{array}{ll}K & \text { permeability of the reservoir } \\ \phi & \text { porosity } \\ \mu & \text { viscosity } \\ C_{t} & \text { compressibility } \\ p w & \text { pressure under the conditions of } u=0 \\ p e & \text { the pressure under the conditions of } u=450 \\ h_{d} & \text { lag distance } \\ N(h) & \text { variation capacity } \\ h_{i} & \text { thickness of layer } i \\ k_{i} & \text { permeability of layer } i \\ h_{t} & \text { total thickness of the reservoir } \\ K_{c} & \text { equivalent permeability } \\ A & \text { cross section area of reservoir } \\ Q & \text { flow rate } \\ r_{w} & \text { shaft radius } \\ Q_{w} & \text { total water injection rate. } \\ R_{i} & \text { resistance of layer } i \\ s o & \text { oil saturation } \\ s o_{\text {max }} & \text { maximum oil saturation } \\ s o r & \text { residual oil saturation } \\ s w & \text { water saturation } \\ s w_{\text {max }} & \text { maximum water saturation } \\ s w r & \text { irreducible water saturation } \\ K_{r o} & \text { oil relative permeability } \\ K_{r w} & \text { water relative permeability } \\ m & \text { characteristic constant } \\ n & \text { characteristic constant } \\ f_{w} & \text { water cut } \\ & \end{array}$




\section{References}

1. Dang, T.Q.C.; Chen, Z.; Nguyen, T.B.N.; Bae, W. The potential of enhanced oil recovery by micellar/polymer flooding in heterogeneous reservoirs. Energy Sources Part A Recovery Util. Environ. Eff. 2014, 36, 1540-1554. [CrossRef]

2. Hou, J.R.; Liu, Z.C.; Dong, M.Z.; Yue, X.A.; Yang, J.Z. Effect of viscosity of alkaline/surfactant/polymer (ASP) solution on enhanced oil recovery in heterogeneous reservoirs. J. Can. Pet. Technol. 2006, 45. [CrossRef]

3. Ehrenberg, S.N. Whole core versus plugs: Scale dependence of porosity and permeability measurements in platform carbonates. AAPG Bull. 2007, 91, 835-846. [CrossRef]

4. Yousef, A.A.; Al-Saleh, S.; Al-Jawfi, M.S. Improved/enhanced oil recovery from carbonate reservoirs by tuning injection water salinity and ionic content. In Proceedings of the Society of Petroleum Engineers (SPE) Improved Oil Recovery Symposium, Tulsa, OK, USA, 4-18 April 2012.

5. Verma, V.K.; Datta, S. Flow in a channel filled by heterogeneous porous medium with a linear permeability variation. Spec. Top. Rev. Porous Media 2012, 3, 201-208. [CrossRef]

6. Hulea, I.N.; Nicholls, C.A. Carbonate rock characterization and modeling: Capillary pressure and permeability in multimodal rocks-A look beyond sample specific heterogeneity. AAPG Bull. 2012, 96, 1627-1642. [CrossRef]

7. Tidwell, V.C.; Wilson, J.L. Heterogeneity, permeability patterns, and permeability upscaling: Physical characterization of a block of massillon sandstone exhibiting nested scales of heterogeneity. SPE Reserv. Eval. Eng. 2000, 3, 283-291. [CrossRef]

8. Chao, H.C.; Rajaram, H.; Illangasekare, T. Intermediate-scale experiments and numerical simulations of transport under radial flow in a two-dimensional heterogeneous porous medium. Water Resour. Res. 2000, 36, 2869-2884. [CrossRef]

9. Correia, M.G.; Maschio, C.; Schiozer, D.J. Integration of multiscale carbonate reservoir heterogeneities in reservoir simulation. J. Pet. Sci. Eng. 2015, 131, 34-50. [CrossRef]

10. Janković, I.; Fiori, A.; Dagan, G. Flow and transport in highly heterogeneous formations: 3. Numerical simulations and comparison with theoretical results. Water Resour. Res. 2003, 39. [CrossRef]

11. Zhou, F.; Yao, G.; Wang, J. Effects of variogram characteristics of coal permeability on CBM production: A case study in Southeast Qinshui Basin, China. Energy Explor. Exploit. 2014, 32, 263-279. [CrossRef]

12. Guadagnini, A.; Riva, M.; Franzetti, S. Flow to a well in a randomly heterogeneous aquifer with truncated multiscale variogram. Dev. Water Sci. 2002, 47, 1299-1306.

13. Matonti, C.; Guglielmi, Y.; Viseur, S.; Bruna, P.O.; Borgomano, J.; Dahl, C.; Marié, L. Heterogeneities and diagenetic control on the spatial distribution of carbonate rocks acoustic properties at the outcrop scale. Tectonophysics 2014, 638, 94-111. [CrossRef]

14. Al-Ameri, T.K.; Al-Khafaji, A.J.; Zumberge, J. Petroleum system analysis of the Mishrif reservoir in the Ratawi, Zubair, North and South Rumaila oil fields, Southern Iraq. GeoArabia 2009, 14, 91-108.

15. Ziauddin, M.E.; Bize, E. The effect of pore scale heterogeneities on carbonate stimulation treatments. In Proceedings of the Society of Petroleum Engineers (SPE) Middle East Oil and Gas Show and Conference, Manama, Bahrain, 11-14 March 2007.

16. Awadeesian, A.M.; Al-Jawed, S.N.A.; Saleh, A.H. Reservoir-scale sequence stratigraphy of Mishrif carbonates and implication to water injection strategy North Rumaila field case. Arab. J. Geosci. 2015, 8, 7025-7040. [CrossRef]

17. Zech, A.; Zehner, B.; Kolditz, O.; Attinger, S. Impact of heterogeneous permeability distribution on the groundwater flow systems of a small sedimentary basin. J. Hydrol. 2016, 532, 90-101. [CrossRef]

18. Kong, X.Y. The application of primitive function and Green function. In Advanced Seepage Mechanics; Press of the University of Science and Technology of China: Hefei, China, 1999. Chapter 4. (In Chinese)

19. Ungaro, F.; Zasada, I.; Piorr, A. Mapping landscape services, spatial synergies and trade-offs. A case study using variogram models and geostatistical simulations in an agrarian landscape in North-East Germany. Ecol. Indic. 2014, 46, 367-378. [CrossRef]

20. Song, H.Q.; Yao, Z.W.; Ming, W.; Kai, S.Y.; Tu, H.O.C. Complicated controllable displacement of equivalent filtrational resistance with several slugs. J. Univ. Sci. Technol. Beijing 2009, 175, 926-932. 